\title{
The Features of Online Tourism Information towards Young Traveler Satisfaction: A Case of Kuching the City of Unity
}

\author{
Siti Aisyah Ya'kob \\ Faculty of Economics and Business \\ Universiti Malaysia Sarawak \\ E-mail: ysaisyah@unimas.my \\ Huong Kui Sieng \\ Faculty of Economics and Business \\ Universiti Malaysia Sarawak \\ E-mail: h.k.sieng0531@ @otmail.my
}

Received: Oct. 14, 2020 Accepted: Nov. 11, 2020 Online published: Dec. 3, 2020

doi:10.5296/jpag.v10i4.17824 URL: https://doi.org/10.5296/jpag.v10i4.17824

\begin{abstract}
Nowadays, online information serves many functions. Despite solely for shopping purposes, the online platform has tremendously served the worldwide community for information search related to travelling. Hence, the features of online information are critically important to be investigated, in understanding the factors that lead to traveler satisfaction. This study investigates the features of online tourism information that lead to satisfaction of the domestic travelers from Peninsular Malaysia and Sabah to Kuching city of Sarawak Borneo. This study proposes two factors, namely credibility of information and segmentation of information. There was a total of 247 sets of questionnaires completed by domestic travelers who visited Kuching city in the year 2015. It is evident that both credibility and segmentation of online tourism information have significant and positive relationships towards traveler satisfaction. In short, the findings of this study offer a clearer view on the credibility and segmentation of online tourism information from domestic traveler's viewpoint.
\end{abstract}

Keywords: online information, tourism, traveler satisfaction, credibility of information, segmentation of information, Sarawak Borneo 


\section{Introduction}

In 1970's, Lancaster approach proved that travelers choose their vacation trip initiated by income and time limitation (Rugg, 1973). A travel agent is one of the traditional ways of searching the information through intermediaries. Travelers normally seek information or opinion from those who have previously travelled to the destination, as well as 'word of mouth' of travel agents (Burgess, Sellitto, Cox, \& Buultjens, 2009). However, the tourism industry has been influenced by technological force, specifically the Internet due to a number of reasons. Most of the travelers use internet for surfing information as an advanced trip planning (Gretzel, 2007). Via internet, travelers are able to communicate and deal directly with the airlines, hotels, rental car companies and others. For example, airline companies distribute tickets and spread the offer prices through their websites (Roma, Zambuto \& Perrone, 2014). Looking into the information from social media such as You Tube, videos and messages can be uploaded for references in making travel decisions (Tseng, Wu, Morrison, Zhang \& Chen, 2015) whilst Facebook enables the users to communicate their experiences and memories to the circle of their friends. Thus, information technology makes contribution in a development of the tourism industry.

Due to this transition, travelers are moving from the conventional concept of authority to the concept of reliability when evaluating the credibility of information (Greenberg et al. 2013). However, the credibility of online tourism information is still a concern in the tourism industry. Some websites are illusory to deceive viewers by giving fake information, sell offerings at lower prices as well as account and privacy hacked (Kirlappos, Sasse, \& Harvey, 2012). Thus, the users feel insecure and worried about the credibility of online tourism information (Conte, 2002). The website's credibility is superior if it comes together with a proper organization of information to serve preferences or taste of travelers from different background (Kastner \& Stangi, 2012). Segmenting the information is helpful for travelers with different cultures and lifestyles to make the decision (Massidda \& Etzo, 2012). In revealing the issues related to online tourism information, this study was carried out to assess the impact of information credibility and information segmentation towards travelers' satisfaction.

The young travelers, age ranged between 18 to 39, were chosen to participate in this survey as they are perceived as motivated and having desire to experience other cultures (Bizirgianni $\&$ Dionysopoulou, 2013). Considering the motivation of young travelers to experience multi-cultural, lifestyle diversity and local history, it is apparent to study on Sarawak Borneo. Sarawak has been positioned as a famous tourism destination that is full with culture and nature of the world (Sarawak Tourism Board, 2014). In particular, the study focuses on travelers who visit Kuching city. Among cities in Sarawak, Kuching city has been awarded the status as the first world's 'city of unity'. The status has been declared by Yayasan 1Malaysia (2015) as a benchmark for unity in races, religions and culture's diversity.

Therefore, the objectives of this study are twofold:

i. To examine the relationship between credibility of information and segmentation of information towards traveler satisfaction and, 
ii. To identify the most influential factor that affects traveler satisfaction in Kuching, Sarawak.

\section{Literature Reviews}

\subsection{The Importance and Challenges of Tourism Industry}

Tourism has been divided into international and domestic categories. Tourism is a popular global leisure activity in the world. The importance of the tourism industry can be viewed in several aspects. In term of the economic aspect, tourism industry has an important role in benefiting the economy. The amount of inbound and outbound travelers will increase with the lower price (Wang, 2009). Besides that, it helps in the nation foreign exchange, bond exchange, economic growth, investment, capital structure, cost structure, and employment generation (Omar, Othman, \& Mohamed, 2014). Information on travel destinations gives the chance for travelers to discover about the local culture, history, lifestyles (Kim, 2014). In the perspective of domestic tourism, it is crucial to understand information-related factors that specifically relevant to attract the domestic travelers. Apart from capitalizing tourism activities and expanding the supply of tourism-related infrastructure, information platform and people-oriented approach should also be considered in the master plan in spurring the national tourism development.

From the aspect of information availability, the uses of the internet make people engage in conversation via electronic word of mouth (eWOM) (Lin, Lu, \& Wu, 2012). Travelers always use the internet to seek information related to trip planning (Gretzel, 2007). Online information also becomes a medium of communication between consumers and suppliers (Tseng et al., 2015). For instance, airlines distribute tickets through websites and spread the offer prices in the website (Roma et al., 2014). In addition, the social media (i.e., YouTube and Facebook) enable travelers to upload photos and messages, be later made available as up to date references for others in making travel decisions (Carvo, 2012; Tseng et al., 2015). Furthermore, it gives the chance for travelers to learn about the local culture, history, and lifestyles (Kim, 2014; Massida \& Etzo, 2012). Pantano and Pietro (2013) reported that 95\% of respondents use the web channel to obtain travel information, and $93 \%$ of the web channel users specifically view the website for their vacation planning purposes. In addition, a number of people utilizing the internet for surfing the details about travel planning and vacation have been increased more than 300\% within 5 years (Pantano \& Pietro, 2013). Therefore, it can be generalized that websites are the favored source of online information for booking travel destination and others. This is due to the general characteristics of individuals who prefer to be well-prepared when they go for travelling as they like security and non-adventurous vacation (Kastner \& Stangi, 2012).

Despite of highlighting the importance of the tourism industry, there are debates related to the credibility of the online information (Lin et al., 2012). The internet has revolutionized the tourism industry and changes the extents of travelers' expectations. With the access of information via online, travelers are changing from the conventional concept of authority to the reliability when measuring the credibility of information (Greenberg et al., 2013). The users feel insecure and concerned about the credibility of the online tourist information 
(Conte, 2002).

\subsection{Satisfaction Towards Online Tourist Information}

Satisfaction is defined as "a person's feeling of contentment or disappointment resulting from the comparison of a product perceived performance", which is related to the expectations (Kotler, 2000). It can be divided into two criteria which are referential and conceptual criteria (Cabanillas, Leiva \& Guardia, 2013). According to Cabanillas et al. (2013), conceptual criteria are the satisfaction through types of people responses and process, meanwhile referential criteria reflect the aspect that happens through the response or process. Previous study has proven the travelers who involved and have experience internet technology will increase the satisfaction level (Maditinos et al., 2010). When pinpointing to the age factor, young travelers are more interested in the destination information and their sensory impact is influenced by invoking design or picture show in the online information (Maditinos \& Theodoridis, 2010).

\subsection{Credibility of Online Tourist Information}

Measuring customers' satisfaction can be done from many dimensions as well-developed measurements have yet to be reported (Wen, 2009). In defining the credibility, it is referred to the authenticity of a source or message made up of expertise and trustworthiness (Lankes, 2008). Looking into the credibility of online tourism information, the information available in the website is commonly shared by travelers (Cooke \& Buckley, 2008). Travelers measure the credibility of information through travel products and images of destinations (Edelman \& Intelliseek, 2005; Wen, 2009). Not only receiving the information, travelers are also able to interact with other travelers by commenting and reviewing (Cooke \& Buckley, 2008; Edelman \& Intelliseek, 2005; Kato, Kurohashi, \& Inui, 2008). Previous literature also reported the credibility of online information is higher than the information obtained from the conventional media (Johnson \& Kaye, 2002). One interesting finding mentioned that if the travelers find the information is interesting, credibility issue will get less consideration (Freeman \& Spyridakis, 2004). They added, the travelers' experience would also influence the judgement of credibility as more experience travelers will think twice in judging the credibility rather than less experienced users. However, Flanagin and Metzger (2007) revealed that travelers are impressed by website attributes such as design, content, structure. Flanagin and Metzger (2007) also identified travelers are more likely to search the information through new website rather than a personal website. Trust, which is one of dimensions evaluated to measure online customer satisfaction is found to affect the level of satisfaction (Kandampully \& Nusair, 2007). Thus, it is hypothesized that credibility of information significantly affects traveler satisfaction towards online tourism information.

\subsection{Segmentation of Information}

Online information is not just for shopping but also for travelling purposes (Information Week, 1998). New and sophisticated technologies make travelers think and analyze the online tourism information prior to the vacation (Amine \& Smith, 2009). Bakos (1991) claimed that segmentation of online tourism information provides a wide presentation of information on 
the website. It enables the travelers to compare the price and bargain information (Bernstein $\&$ Awe, 1999). Even though online information is seen as giving an advantage to travelers, the businesses view this matter differently. The online information on the internet contributes to pricing transparency and price competitive (Wen, 2009). Beside segmenting information based on prices, information can be segmented based on features such as natural, cultural, recreational and climate parts to allow travelers choose their preferred destination (Leisen, 2001). Then, segmentation of educational information has been introduced which comprises of the mixture of discovery, excitement, exploration, and mental stimulation targeting leads to high satisfaction level (Packer, 2006). Traveler satisfaction can be increased when the information providers improve their relationship with customers by promoting the proper segmentation of information on official websites (Sussmann et al., 1996). In consistent with the evidences from Packer (2006) and Sussmann et al., (1996), thus, it is hypothesized that segmentation of information significantly affects traveler satisfaction towards tourism online information.

\section{Research Methodology}

\subsection{Sampling}

The sampling frame used in this study was the statistic of visitor arrivals into Sarawak from January to August 2015. The statistic is considered truthful as it is obtained from the official website of Ministry of Tourism Sarawak (2015). Among the eight divisions in Sarawak, Kuching was selected for its recent recognition as the benchmark for unity in races, religions and culture's diversity (Yayasan 1 Malaysia, 2015). With a total of 1157595 domestic travelers from Peninsular Malaysia and Sabah who visited Sarawak (Ministry of Tourism Sarawak, 2015), the sample size of 247 with a margin of error of $7.00 \%$ was calculated using Slovin's formula. By a way of a convenient sampling, the youths were chosen as the unit of analysis as they are perceived as motivated and having desire to experience other cultures (Bizirgianni \& Dionysopoulou, 2013).

\subsection{Research Instrument}

The questionnaire was formed using the items that have been validated earlier (Cai \& Jun, 2003; Chiou, Wu \& Sung, 2009; Ha \& Janda, 2014; San-Martin \& Lopez, 2013). The questionnaire comprises of four sections. Three of four sections were measured by using a five-point Likert scale. The scale used for credibility and segmentation of online information sections describe the level of respondents' agreement $(1=$ Strongly disagree; $2=$ Disagree; $3=$ Neutral; $4=$ Agree; $5=$ Strongly agree) while the traveler satisfaction section describes the level of satisfaction ( $1=$ Very dissatisfied; $2=$ Dissatisfied; $3=$ Neutral; 4=Satisfied; $5=$ Very dissatisfied). The final section measured the respondents' background information.

\subsection{Data Collection Method}

A self-administered survey was carried out, enabling the respondents to complete the questionnaire at their own convenience. The questionnaire was distributed within one month by approaching the potential respondents directly. A direct approach is preferred for the precision and completeness of the questionnaire (Brinkman, 2009). Out of 300 sets of 
questionnaire distributed, 247 sets are completed for analysis. Thus, the response rate would be $82.33 \%$.

\section{Data Analysis and Findings}

\subsection{Respondents' Profile}

The majority of the respondents are female (61.90\%). Most of them are between 21 to 25 years old $(95.10 \%)$. The analyses disclosed that the majority of the respondents have up to first degree level qualifications $(70.40 \%)$. From the total of 247 respondents, $96.00 \%$ are single, $2.80 \%$ of them are married and $1.20 \%$ of them declare other status. The analyses also discovered $63.20 \%$ of respondents claim their interest in travelling.

\subsection{Factor Analysis}

Albeit the variables have been proven by prior studies, the principal-components analysis is performed to identify a new set of variables that are statistically significant to suit the present samples and situation. In factor analysis, the degree of factor loading is an indicator to select the items for the analysis. The rule of thumb of the degrees of factor loadings is indicated by the range of factor loading and description of correlation [Very high factor loading $(>0.6)=$ the variable describes the factor very well; High factor loading $(>0.3)=$ the variable describes the factor well; Low loading $(<0.3)=$ should be ignored] (Bradley, 2007).

Factor analysis was performed on the 17 items of the independent variables in order to reduce the total number of items to a more manageable number (Lee, Kwon \& Severence, 2007). The Keiser-Meyer-Olkin (KMO) and Barlett's test of Sphericity were performed to confirm if factor analysis could be done or not (Tabachnick \& Fidell, 2001). The KMO value is 0.798 and the Barlett's test is statistically significant (Chi-Square $=482.450, \mathrm{p}<0.000$ ) which is adequate for factor reduction procedure.

Referring to Table 1, two components were extracted after three iterations, with Eigenvalue more than 1 and contributing $61.52 \%$ of the total variance. The two components were examined namely segmentation of information and credibility of information. Therefore, the findings support the suggestions of at least three observed items with Eigenvalue more than 1 (de Run et al., 2009). The factors loadings of all items are presented in Table 1 for the features of online tourism information:

Table 1. Rotated Component Matrix for the Features of Online Tourism Information

\begin{tabular}{lcc}
\hline \multicolumn{1}{c}{ Variables } & $\begin{array}{c}\text { Credibility of } \\
\text { Information }\end{array}$ & $\begin{array}{c}\text { Segmentation } \\
\text { of Information }\end{array}$ \\
\hline I feel I can trust online tourism information. & 0.818 & \\
I think that online tourism information was reliable. & 0.762 & \\
I think that online tourism information fulfills its & 0.755 \\
promises. & & 0.591 \\
The organization and structure of online tourism & & 0.867 \\
information website was logical. & & \\
When design the range of tourism information, it takes \\
the accounts of traveler wishes.
\end{tabular}


When design the range of tourism information, it takes

the accounts of traveler needs.

The contents in the Web site were easy to understand

$\%$ of Variance

Extraction Method: Principal Component Analysis.

61.522

Rotation Method: Varimax with Kaiser Normalization.

a. Rotation converged in 3 iterations.

\subsection{Reliability Analysis}

Reliability analysis was then performed to assess the accuracy, precision and internal consistency of the items (Cooper \& Schindler, 2008) used to measure the factors i.e. segmentation of information, credibility of information and traveler satisfaction. The Cronbach's alpha value of the three factors in the table is considered as acceptable since all are above 0.6 (Hair, Bush \& Ortinau, 2009). Table 2 illustrates the results of the reliability test for segmentation of information is 0.685 , credibility of information is 0.772 and traveler satisfaction is 0.859 . Successively, the reliability analysis assures that all items have acceptable reliability, which is an alpha value greater than 0.6 .

Table 2. Reliability Analysis of Extracted Factors

\begin{tabular}{lcc}
\hline Dimensions & No of items tested & Cronbach's Alpha \\
\hline Segmentation of information & 3 & 0.685 \\
Credibility of information & 4 & 0.772 \\
Traveler satisfaction & 8 & 0.859 \\
\hline
\end{tabular}

\subsection{Multiple Regression Analysis}

Multiple regression analysis was performed and the results were summarized in Table 3 . The results showed that the $\mathrm{R}$ square of the model was 0.489 which means that $48.9 \%$ of the variance in traveler satisfaction (dependent variable) can be explained by the two independent variables namely credibility of information and segmentation of information. The results of the ANOVA test showed that the model is statistically significant (sig. $=0.000, p<0.05$ ) with F-value 116.647. The result indicated that both of the factors were significantly related to traveler satisfaction. The standardized beta coefficient indicates the relative importance of each of the indicators. Credibility of information $(\beta=0.449, \mathrm{p}=0.000)$, generated the highest positive and significant influence on traveler satisfaction and this is followed by segmentation of information $(\beta=0.361, \mathrm{p}=0.000)$.

Table 3. Multiple Regression Analysis

\begin{tabular}{lccc}
\hline & $\begin{array}{c}\text { Standardised Coefficient } \\
(\text { Beta) }\end{array}$ & t-value & Sig. \\
\hline Credibility of information & 0.449 & 8.589 & 0.000 \\
Segmentation of information & 0.361 & 6.915 & 0.000 \\
\hline a. Dependent Variable: Traveler satisfaction & & \\
R Square $=0.489$ & F-Value $=116.674$ & & \\
Adjusted R Square $=0.485$ & Sig. $=0.000$ & & \\
\hline
\end{tabular}


Based on the results above, it is concluded that two hypotheses proposed earlier were supported (Table 4).

Table 4. Hypotheses Testing

\begin{tabular}{lll}
\hline & \multicolumn{1}{c}{ Hypotheses } & Findings \\
\hline $\mathbf{H}_{\mathbf{1}}:$ & $\begin{array}{l}\text { There is a significant and positive relationship between } \\
\text { segmentation of information and traveler satisfaction. }\end{array}$ & Supported \\
$\mathbf{H}_{\mathbf{2}}:$ & $\begin{array}{l}\text { There is a significant and positive relationship between } \\
\text { credibility of information and traveler satisfaction. }\end{array}$ & Supported \\
\hline
\end{tabular}

\section{Discussion and Conclusion}

While the Internet is commonly used for information search activity prior to travel activities (Gretzel, 2007), today's travel and tourism businesses need to understand and develop effective means to connect the travelers. Within the context of technological change, understanding and capitalizing on the segmented information and targeted tourists (i.e., international vs. domestic; retiree, family vs. young traveler) could create competitive advantages to tourism destinations. It is crucial for business operators to provide rich and relevant information for travel planning that can cater the evolving customer needs.

The findings demonstrate that social media and other emergent forms of online tourism information are having an enormous impact on travel planning. Interestingly, two predictors of online tourism information, namely segmentation of information and credibility of information were examined for their effect on traveler satisfaction. The multiple regression analysis has shown that the traveler satisfaction on online tourism information is found to be significantly influenced by both credibility and segmentation of information. In terms of information credibility, the finding is consistent with Johnson and Kaye (2002) who compared the credibility of information obtained from online and offline. The information obtained online was reported gaining higher credibility in comparison to the information gathered offline. The previous empirical study also proved that the credibility of information gets less consideration if the travelers find the information is remarkable (Freeman \& Spyridakis, 2004). In terms of information segmentation, the finding supports prior study by Sussmann et al., (1996) in which satisfaction is increased by proper segmentation of information in specific website. This finding also lends a support from Packer (2006) who proved that the segmentation of educational information in the website leads to a high level of satisfaction. Furthermore, credibility of information was found to be the most influential factor that affects traveler satisfaction. The findings also show that these two predictors only predict slightly more than 40 percent of the variance in traveler satisfaction.

This present study has a few limitations that might affect its interpretations of the findings. First, the sample of this study is restricted to domestic travelers from Peninsular Malaysia and Sabah who visited Kuching city. Future studies may focus on the international travelers who visit Kuching city, so that results can be generalized to a larger population. In this study, only two predictors were examined. Future research should also consider investigating the effect 
of other variables in addition to the those that have been examined in this present article.

In conclusion, the study has found that the credibility and segmentation of online tourism information significantly affect the satisfaction of travelers from Peninsular Malaysia and Sabah to Kuching city. It is prudent to note that both criteria should be linked to business strategies, and to characterize the available online tourism information for engaging more targeted travelers in travel planning. As such, continuous efforts in providing and maintaining credibility and segmented online tourism information will eventually change the traditional structure of travel and tourism businesses.

\section{Acknowledgement}

This paper is supported by the Faculty of Economics and Business, Universiti Malaysia Sarawak (UNIMAS).

\section{References}

Amine, L. S., \& Smith, J. A. (2009). Challenges to modern consumer segmentation in a changing world: the need for a second step. Multinational Business Review, 17(3), 71-100. https://doi.org/10.1108/1525383X200900018

Bakos, J. Y. (1991). A strategic analysis of electronic marketplaces. MIS Quarterly, 15(3), 295-310. https://doi.org/10.2307/249641

Bernstein, J., \& Awe, S. C. (1999). "Wired travelers": travel and tourism web sites. Reference Service Review, 27(4), 364-375.

Bizirgianni, I., \& Dionysopoulou, P. (2013). The influence of tourist trends of youth tourism through social media (SM) and communication technologies (ICTs). Procedia - Social and Behavioral Sciences, 73, 652-660. https://doi.org/10.1016/j.sbspro.2013.02.102

Bradley, N. (2007). Marketing Research Tools and Techniques. New York: Oxford University Press.

Brinkman, W. P. (2009). Design of a questionnaire instrument. Handbook of Mobile Technology Research Methods, 31-57.

Burgess, S., Sellitto, C., Cox, C., \& Buultjens, J. (2009). Trust perception of online travel information by different content creators: Some social and legal implications. Springer Science + Business Media, 13, 221-235. https://doi.org/10.1007/s10796-009-9192-x

Cabanillas, F. L., Leiva, F. M., \& Guardia, F. R. (2013). The determinants of satisfaction with e-banking. Industrial Management and Data Systems, 113(5), 750-767. https://doi.org/10.1108/02635571311324188

Cai, S., \& Jun, M. (2003). Internet users' perception of online service quality: a comparison of online buyers and information searchers. Managing Service Quality: An International Journal, 13(6), 504-519. https://doi.org/10.1108/09604520310506568

Carvo, S. (2010). Embracing user generated content within destination management 
organizations to gain a competitive insight into visitors profiles. Worldwide Hospitality and Tourism Themes, 2(4), 376-382. https://doi.org/10.1108/17554211011074038

Chiou, Jyh-Shen, Wu, Lei-Yu \& Sung, Yi-Ping. (2009). Buyer satisfaction and loyalty intention in online auctions. Journal of Service Management, 20(5), 521-543. https://doi.org/10.1108/09564230910995125

Conte, R. (2002). Reputation in infosocieties. Reputation in Artificial Societies.

Cooke, M., \& Buckley, N. (2008). Web 2.0, social networks and the future of market research. International Journal of Market Research, 50(2), 267-292. https://doi.org/10.1177/147078530805000208

Cooper, D. R., \& Schindler, P. S. (2008). Business Research Methods (Internatio.). New York: McGraw Hill.

de Run, E. C., May-Chiun, L., \& Heriyadi, K. (2008). Basic Analysis: A Guide for Students and Researchers. Kuching: Jade Press Enterprise.

Edelman and Intelliseek (2005). Trust Media: how real people are finally being heard, the 1.0 guide to the blogosphere for marketers and company stakeholders. Retrieved October 30, 2015 , from

http://kevin.lexblog.com/wp-content/uploads/sites/111/2005/04/Edelman-1.0-on-Blogosphere .pdf

Flanagin, A. J., \& Metzger, M. J. (2007). The role of site features, user attributes, and information verification behaviors on the perceived credibility of web-based information. New Media \& Society, 9, 319-42. https://doi.org/10.1177/1461444807075015

Freeman, K. S., \& Spyridakis, J. H. (2004). An examination of factors that affect the credibility of online health information. Technical Communication, 51(2), 239-63.

Greenberg, S., Yaari, E., \& Bar-Ilan, J. (2013). Perceived credibility of blogs on the internet the influence of age on the extent of criticism. Aslib Proceedings: New Information Perspectives, 65(1), 4-18. https://doi.org/10.1108/00012531311297159

Gretzel, U. (2007). Online travel review study: Role and impact of online travel reviews.

Ha, Hong-Youl \& Janda, S. (2014). The effect of customized information on online purchase intentions. Internet Research, 24(4), 496-519. https://doi.org/10.1108/IntR-06-2013-0107

Hair, J. F., Bush, R. P., \& Ortinau, D. J. (2009). Marketing Research: In a Digital Information Environment (Fouth Edit.). New York: McGraw-Hill.

Hair, J., Bush, R., \& Ortinau, D. (2009). Marketing Research: In a Digital Information Environment. Fourth Edition. McGraw-Hill, New York.

Information Week (1998). Airlines, online agencies, battle for customers. Information Week, 708(9), 31.

Johnson, T. J., \& Kaye, B. K. (2002). Webelievability: a path model examining how 
convenience and reliance predict online credibility. Journalism \& Mass Communication Quarterly, 79(3), 619-642. https://doi.org/10.1177/107769900207900306

Kandampully, J., \& Nusair, K. (2007). The antecedents of customer satisfaction with online travel services: a conceptual model. European Business Review, 20(1), 4-19. https://doi.org/10.1108/09555340810843663

Kastner, M., \& Stangi, B. (2012). Mapping segments accessing user-generated content and website applications in a joint space. International Journal of Culture, Tourism and Hospitality Research, 6(4), 389-404. https://doi.org/10.1108/17506181211265103

Kato, Y., Kurohashi, S., \& Inui, K. (2008). Information credibility on the web. Internet Research, 18(2). https://doi.org/10.1108/intr.2008.17218baa.001

Kim, J.H. (2014). The antecedents of memorable tourism experiences: The development of a scale to measure the destination attributes associated with memorable experiences. Tourism Management, 44, 34-45. https://doi.org/10.1016/j.tourman.2014.02.007

Kirlappos, I., Sasse, M. A., \& Harvey. N. (2012). Why trust seals don't work: a study of users perceptions and behavior. Springer-Verlag Berlin Heidelberg, 308-324. https://doi.org/10.1007/978-3-642-30921-2_18

Kotler, P. P. (2000). Marketing Management (International Edition). New Jersey: Prentice-Hall.

Lankes, R. D. (2008). Credibility on the internet: shifting from authority to reliability. Journal of Documentation, 64(5), 667-686. https://doi.org/10.1108/00220410810899709

Lee, C. W., Kwon, I.W. G., \& Severance, D. (2007). Relationship between supply chain performance and degree of linkage among supplier, internal integration, and customer. Supply Chain Management: An International Journal, 6(12), 444-452. https://doi.org/10.1108/13598540710826371

Leisen, B. (2001). Image segmentation: the case of a tourism destination. Journal of Services Marketing, 15(1), 49-66. https://doi.org/10.1108/08876040110381517

Lin, T. M. Y., Lu, K. Y., \& Wu, J. J. (2012). The effects of visual information in eWOM communication. Journal of Research in Interactive Marketing, 6(1), 7-26. https://doi.org/10.1108/17505931211241341

Maditinos, D. I., \& Theodoridis, K. (2010). Satisfaction determinants in the Greek online shopping context. Information Technology \& People, 23(4), 312-329. https://doi.org/10.1108/09593841011087789

Massidda, C., \& Etzo, I. (2012). The determinants of Italian domestic tourism: A panel data analysis. Tourism Management, 33, 603-610. https://doi.org/10.1016/j.tourman.2011.06.017

Ministry of Tourism Sarawak (2015). Visitors arrival into Sarawak. Retrieved October 30, 2015,

http://www.mot.sarawak.gov.my/upload/file_folder/VISITOR\%20ARRIVAL\%202015\%20jul 
y.pdf

Omar, S. I., Othman, A.G., \& Mohamed, B. (2014). The tourism life cycle: an overview of Langkawi Island, Malaysia. International Journal of Culture, Tourism, and Hospitality Research, 8(3), 272-289. https://doi.org/10.1108/IJCTHR-09-2013-0069

Packer, J. (2006). Learning for fun: the unique contribution of educational leisure experiences. $\begin{array}{llll}\text { Curator: } \quad \text { The } & \text { Museum } & \text { 329-344. }\end{array}$ https://doi.org/10.1111/j.2151-6952.2006.tb00227.x

Pantano, E., \& Pietro, L. D. (2013). From e-tourism to f-tourism: emerging issues from negative tourists online review. Journal of Hospitality and Tourism Technology, 4(3), 211-227. https://doi.org/10.1108/JHTT-02-2013-0005

Ponnan, R. (2013). Broadcasting and socially responsible rural tourism in Labuan, Malaysia. Worldwide Hospitality and Tourism Themes, 5(4), 398-411. https://doi.org/10.1108/WHATT-03-2013-0019

Gretzel, U. (2007). Online travel review study: Role and impact of travel reviews. Retrieved September 30, 2015, from http://www.tripadvisor.in/pdfs/OnlineTravelReviewReport.pdf

Roma, P., Zambuto, F., \& Perrone, G. (2014). Price dispersion, competition, and the role of online travel agents: Evidence from business routes in the Italian airline market. Transportation Research Part E, 69, 146-159. https://doi.org/10.1016/j.tre.2014.06.004

Rugg, D. (1973). The choice of journey destination: a theoretical and empirical analysis. Review of Economics and Statistics, 55(1), 64-72. https://doi.org/10.2307/1927995

San-Martin, S., \& Lopez-Catalan, B. (2013). How can a mobile vendor get satisfied customers?. Industrial Management \& Data Systems, 113(2), 156-170. https://doi.org/10.1108/02635571311303514

Sarawak Tourism Board (2015). Introduction. Retrieved October 30, 2015, from http://sarawaktourism.com/\#introduction

Tabachnick, B. G., \& Fidell., L. S. (2001). Using multivariate statistics (Fourth Edi.). Boston, MA: Allyn \& Bacon.

Tseng, C., Wu, B., Morrison, M. A., Zhang, J., \& Chen, Y. C. (2015). Travel blogs on China as a destination image formation agent: A qualitative analysis using Leximancer. Tourism Management, 46, 347-358. https://doi.org/10.1016/j.tourman.2014.07.012

Wang, Y.S. (2009). The impact of crisis event and macroeconomic activity on Taiwan's international inbound tourism demand. Tourism Management, 30, 75-82. https://doi.org/10.1016/j.tourman.2008.04.010

Wen, I. (2009). Factor affecting the online travel buying decision: a review. International Journal of Contemporary Hospitality Management, 21(6), 752-765. https://doi.org/10.1108/09596110910975990 
Yayasan 1 Malaysia (2015). The Kuching international forum on unity (KIFU). Retrieved August 27, 2015, from http://yayasan1malaysia.org/events/kifu/\#.Vm_sm17Ujcs

\section{Copyright Disclaimer}

Copyright for this article is retained by the author(s), with first publication rights granted to the journal.

This is an open-access article distributed under the terms and conditions of the Creative Commons Attribution license (http://creativecommons.org/licenses/by/4.0/). 